\title{
PERFIL EPIDEMIOLÓGICO Y MOLECULAR DE RICKETTSIOSIS EN LOCALIDADES DE FRONTERA PERUANA
}

\author{
Rosa Palacios-Salvatierra 1,a, Elizabeth Anaya-Ramírez ${ }^{1, a}$, Julio Juscamayta-López 1,b, Omar Cáceres-Rey 1,c, \\ Leonardo Mendoza-Uribe ${ }^{1, d}$, Patricia Mosquera-Visaloth ${ }^{1, e}$, Fátima Conceição-Silva 2,f
}

\begin{abstract}
RESUMEN
Objetivos. Determinar circulación de rickettsias durante los años 2010 al 2011 en localidades fronterizas de cuatro regiones del Perú, y sus características clínicas epidemiológicas y moleculares. Materiales y métodos. Estudio transversal realizado en Tumbes, Tacna, Madre de Dios y Loreto. Se obtuvo datos clínicos epidemiológicos y muestras de sangre total para cultivo y para ensayo de inmunofluorescencia indirecta (IFI). Fue utilizado ADN extraído de cultivos de leucocitos y de ectoparásitos, aquellos genes específicos para rickettsias que amplificaron exitosamente fueron secuenciados y analizados. Resultados. El 33,8\% de los encuestados portaba anticuerpos a rickettsias; en Loreto $21,7 \%$, en Madre de Dios 33,0\%, en Tacna 48,2\% y en Tumbes 33,3\%, encontrándose seropositividad en más del $40 \%$ de aislamientos confirmados por IFI. Las pruebas moleculares evidenciaron la presencia de Rickettsia felis en Ctenocephalides felis de perros y gatos de Tacna y una especie recientemente reportada para Latinoamérica: Candidatus Rickettsia asemboensis en pulgas Ctenocephalides felis de gatos y perros de Loreto y Madre de Dios. De la población estudiada, el $81,4 \%$ informó antecedentes de contacto con ectoparásitos, el 22,6\% eran asintomáticos y el $27,8 \%$ habitaban viviendas sin agua ni desagüe, con piso de tierra. Conclusiones. Evidencias serológicas y moleculares confirman la circulación de rickettsias en las localidades fronterizas estudiadas, con predisponentes epidemiológicos, demostrándose presencia de dos especies: Rickettsia felis y Candidatus Rickettsia asemboensis, las que representarían una amenaza potencial para la salud de los pobladores.
\end{abstract}

Palabras clave: Infecciones por Rickettsia, Perú, Epidemiología molecular, Vectores artrópodos (fuente: DeCS BIREME).

\section{EPIDEMIOLOGICAL AND MOLECULAR PROFILE OF RICKETTSIOSIS IN PERUVIAN BORDER LOCATIONS}

\begin{abstract}
Objectives. To determine the circulation of Rickettsia in the years 2010 and 2011 in border locations in four regions of Peru and their clinical epidemiological and molecular characteristics. Materials and Methods. A cross-sectional study was carried out in Tumbes, Tacna, Madre de Dios, and Loreto. Whole blood samples were obtained from participants for culture and indirect immunofluorescence (IIF) testing. The DNA taken from leukocytes and ectoparasite cultures was used, and those genes detected for Rickettsia that were successfully amplified were sequenced and analyzed. Results. A total of $33.8 \%$ of those surveyed carried Rickettsia antibodies $(21.7 \%$ in Loreto, $33.0 \%$ in Madre de Dios, $48.2 \%$ in Tacna, and $33.3 \%$ in Tumbes). Seropositivity was confirmed with IIF in over $40 \%$ of isolates. Molecular tests showed the presence of Rickettsia felis in Ctenocephalides felis of dogs and cats in Tacna and a recently reported species for Latin America, Candidatus Rickettsia asemboensis, in fleas of cats and dogs in Loreto, Madre de Dios, and Tacna. Of the population studied, $81.4 \%$ reported a history of contact with ectoparasites, $22.6 \%$ were asymptomatic, and $27.8 \%$ lived in earthen-floored homes without water or drainage. Conclusions. Serological and molecular evidence confirms the circulation of Rickettsia in the border locations studied, with predisposing epidemiological factors. Tests confirm the presence of two species, Rickettsia felis and Candidatus Rickettsia asemboensis, which represent a potential threat to the health of the inhabitants.
\end{abstract}

Keywords: Rickettsia infection, Peru, Molecular epidemiology, Arthropod vectors(source: MeSH NLM).

\footnotetext{
Centro Nacional de Salud Pública, Instituto Nacional de Salud, Lima, Perú
}

Laboratorio de Inmunoparasitología, Instituto Oswaldo Cruz - Fio Cruz - Rio de Janeiro, Brasil

Bióloga, magister en Salud Pública; ${ }^{\mathrm{b}}$ biólogo genetista, magister en Biología Molecular, ${ }^{\mathrm{c}}$ biólogo, magister en Biología Molecular; ${ }^{\mathrm{d}}$ biólogo; ${ }^{\mathrm{e}}$ técnica de laboratorio; ${ }^{\mathrm{I}}$ médica, doctora en Ciencias

El presente estudio contiene parte de la información de la Tesis para optar el grado de Maestría en Salud Pública de Rosa Palacios Salvatierra en el marco del Convenio Instituto Nacional de Salud con la Escuela de Salud Pública Sergio Arauca de la Fundación Oswaldo Cruz de Brasil. Recibido: 20/01/2016 Aprobado: 22/02/2017 En línea: 23/03/2017

Citar como: Palacios-Salvatierra R, Anaya-Ramírez E, Juscamayta-López J, Cáceres-Rey O, Mendoza-Uribe L, Mosquera-Visaloth P, Conceição-Silva F. Perfil epidemiológico y molecular de Rickettsiosis en localidades de frontera peruana. Rev Peru Med Exp Salud Publica. 2017;34(1):76-84. doi: 10.17843/ rpmesp.2017.341.2769 


\section{INTRODUCCIÓN}

Las zonas fronterizas del territorio peruano están constituidas por localidades alejadas de los servicios básicos de saneamiento y salud e influenciadas básicamente por sus ecosistemas y su situación demográfica, delineándose una dinámica con patrones epidemiológicos característicos para la transmisión y diseminación de agentes infecciosos, es el caso de algunas enfermedades asociadas a vectores como las causadas por rickettsias, tal como ha venido ocurriendo a través del tiempo en diversas latitudes ${ }^{(1)}$.

Las infecciones causadas por rickettsias constituyen enfermedades sistémicas febriles que afectan a grupos poblacionales diversos, incluyendo individuos de cualquier edad, independientemente de su estado inmune ${ }^{(2)}$. Su presentaciónestáinfluenciada porfactores medioambientales, como el cambio climático y el incremento de la humedad en verano, lo cual crea condiciones propicias para la movilización de los agentes transmisores y su desplazamiento a través de fronteras internacionales ${ }^{(3)}$. En general, se sabe poco acerca de la carga de enfermedad por rickettsiosis y de sus ciclos de transmisión en muchas regiones del mundo ${ }^{(4)}$, en especial en América Latina ${ }^{(5)}$. No obstante, la información disponible sugiere que la transmisión en Sudamérica, por ejemplo de la denominada "fiebre manchada", es más prevalente que la reportada ${ }^{(6)}$.

En Perú, existen reportes de circulación de anticuerpos para rickettsias en localidades con características favorables para presencia de ectoparásitos (piojos, pulgas, garrapatas) ${ }^{(7)}$, además se han llevado a cabo estudios moleculares con artrópodos vectores procedentes de varias localidades del territorio peruano ${ }^{(8-11)}$; no obstante, hace falta mayor información acerca del entorno epidemiológico asociado y las especies de rickettsias que estarían circulando, este conocimiento podría repercutir en el manejo clínico de los pacientes con cuadros febriles inespecíficos y en la prevención de la enfermedad para grupos en riesgo ${ }^{(12)}$.

Las zonas consideradas para el presente estudio fueron seleccionadas por exhibir características epidemiológicas favorables para la presentación de rickettsiosis, el objetivo del estudio fue evidenciar la circulación de rickettsias durante los años 2010 al 2011, en zonas de frontera peruana, además de describir sus características clínico epidemiológicas y moleculares.

\section{MATERIALES Y MÉTODOS}

\section{DISEÑO DEL ESTUDIO}

Se llevó a cabo un estudio de diseño transversal en localidades de la frontera peruana, específicamente durante los meses de abril, mayo, junio del 2010 en Loreto y Madre de Dios y en Tumbes y Tacna en marzo, abril y mayo del 2011, efectuándose encuestas y obtención de muestras con el propósito de identificar la circulación de rickettsias.

\section{POBLACIÓN}

El estudio se realizó en localidades ubicadas en cuatro regiones de frontera del Perú, cuyas características geográficas ${ }^{(13)}$ y climatológicos condicionantes ${ }^{(14)}$ para la presentación de enfermedades transmisibles como las rickettsiosis, se describen a continuación:

Tumbes, es una región ubicada al noroeste del Perú, es una zona costera que se encuentra a 5 a $7 \mathrm{~m}$ de altitud, posee un clima muy cálido, la temperatura media anual máxima y mínima es 32,1 y $22{ }^{\circ} \mathrm{C}$ respectivamente. La precipitación media anual es de $350,5 \mathrm{~mm}$. El clima varía con la ocurrencia del fenómeno de El Niño, principalmente con las lluvias.

Loreto, ubicada en la zona oriental del Perú, selva baja norte, se encuentra a $105 \mathrm{msnm}$, en la provincia de Maynas, la temperatura media anual máxima es de $31^{\circ} \mathrm{C}$ a $36^{\circ} \mathrm{C}$ y la media anual mínima de $21^{\circ} \mathrm{C}$. con promedio de $26^{\circ} \mathrm{C}$. Mazán es un distrito rural y ribereño con poblados dispersos, altitud de 108 msnm, al margen derecho del rio Napo.

Tacna es una región ubicada al sur oeste de Perú, se encuentra a $800 \mathrm{msnm}$, es un valle costero con ambiente subtropical árido, clima seco, con ausencia de lluvias regulares y una temporada de lloviznas que se extiende desde junio hasta agosto. La temperatura es moderada y tiene un promedio anual de $18,6{ }^{\circ} \mathrm{C}$, con una máxima de $32^{\circ} \mathrm{C}$ y una mínima de $10^{\circ} \mathrm{C}$.

Madre de Dios, es una región ubicada en la parte sur oriental, se encuentra a $308 \mathrm{~m}$ de altitud, con temperatura promedio de $38{ }^{\circ} \mathrm{C}$. El clima varía entre húmedo y subhúmedo, con precipitaciones que oscilan entre 1500 y $3000 \mathrm{~mm}$ anuales. En los meses de agosto y setiembre el clima sufre a veces influencias de masas de aire frío que llegan desde el sureste del continente americano ocasionando el friaje que puede llegar a los $8^{\circ} \mathrm{C}$.

\section{MUESTRA}

Para determinar el tamaño de muestra se consideró cada región por separado, haciéndose una estimación de una prevalencia del $50 \%$, por reportes previos de la infección en base a serología, nivel de confianza del 95\% con error del $5 \%$ y posible rechazo a participar de un $15 \%$, se consideró suficiente y representativa una muestra de 380 individuos en promedio para cada una de las regiones.

Las encuestas fueron efectuadas aleatoriamente, habiendo seleccionado previamente las localidades de estudio en base a la población existente en cada una 
de ellas y guiándose con un mapa de cada distrito, se distribuyó cada área de estudio en manzanas numeradas, con sucesivos sorteos de dichos números para iniciar los muestreos y del sentido del avance del muestreo (horario o antihorario) y el salto de una vivienda hacia otra. En localidades sin distribución urbana, viviendas rurales alejadas una de otra, fueron seleccionadas asignándoles un número de identificación a cada centro poblado.

Se obtuvo muestras de artrópodos ectoparásitos de animales domésticos vinculados a los participantes en la encuesta.

\section{CRITERIOS DE INCLUSIÓN Y EXCLUSIÓN}

Se incluyeron a individuos de diversos grupos de edad, que estuvieran residiendo con permanencia mínima de un mes, en alguna de las localidades de las cuatro regiones y que aceptaron participar después de recibir la información correspondiente al estudio y firma del consentimiento informado. También se incluyeron los artrópodos parásitos capturados en animales domésticos y/o peridomiciliarios de las viviendas de los sujetos encuestados al momento del estudio.

Se excluyeron a personas en tratamiento con antibióticos, con diagnóstico de enfermedad crónica terminal, inmunosuprimidos o con enfermedad psiquiátrica mayor (psicosis o esquizofrenia). Además, se excluyeron a aquellos que no aceptaron participar en el estudio ni firmar el consentimiento informado.

\section{VARIABLES}

Se consideraron como variables sociodemográficas a la edad, sexo y procedencia de los participantes. Las variables ecoepidemiologicas hacen referencia a los antecedentes de contacto con artrópodos ectoparásitos y/o animales domésticos intra o peridomiciliarios, al tipo de vivienda, saneamiento o disponibilidad de agua y desagüe, y la realización de viajes previos. Como variables clínicas se consideró a la sintomatología al momento de la obtención de las muestras, como variables serológicas se consideró a la presencia o ausencia de anticuerpos para Rickettsia $s p$, asimismo para los análisis moleculares se determinó las secuencias parciales de cuatro genes: $h t r A$, gltA, ompA y ompB.

\section{PROCEDIMIENTO}

La explicación de las características del estudio, las posibles molestias de la toma de muestra y la invitación a participar lo realizaron dos personas del equipo de campo. Luego de la firma del consentimiento informado, se procedió a obtener 1 a $5 \mathrm{~mL}$ de sangre venosa en condiciones de esterilidad, en dos tubos Vacutainer $§$, uno con anticoagulante y otro sin anticoagulante, conservando ambos a $4{ }^{\circ} \mathrm{C}$.
En el laboratorio se procedió a extraer de la sangre total con anticoagulante, mediante centrifugación con polímero de sucrosa para establecer gradiente de densidades, el paquete de células blancas, que fue inoculado en línea celular Vero ATCC CRL-1586 (riñón de mono verde africano Cercopithecus aethiops), a fin de aislar rickettsias, utilizando medio Eagle con sales de Earle), suplementado con L-glutamina, aminoácidos no esenciales, piruvato de sodio y suero bovino fetal al $5 \%$, para su propagación y mantenimiento, siendo incubados durante 15 días a $34{ }^{\circ} \mathrm{C}$ en presencia de $5 \%$ de $\mathrm{CO}_{2}{ }^{(15)}$, para ser luego cosechados y verificada su viabilidad, siendo el criterio de positividad la prueba de Inmunofluorescencia indirecta (IFI) para detección de antígeno rickettsial (16), empleando conjugado comercial y controles de referencia positivo y negativo también comerciales, de reconocida efectividad $y$ reproducibilidad.

De las muestras sin anticoagulante se separaron los sueros para evaluar presencia de anticuerpos específicos a rickettsias mediante IFI, empleando láminas impregnadas in house (preparadas en el Laboratorio de Metaxénicas Bacterianas del Instituto Nacional de Salud de Perú) con antígeno de Rickettsia akari (grupo transicional) filogenéticamente relacionado al grupo de las fiebres manchadas y con antígeno de Rickettsia canadensis (grupo ancestral), filogenéticamente relacionado al grupo Tifus ${ }^{(17)}$.

Los artrópodos ectoparásitos fueron identificados y clasificados empleando guías taxonómicas para pulgas ${ }^{(18)}$ y garrapatas ${ }^{(19)}$, en grupos de 2 a 5 individuos por muestra, desinfectados en alcohol $70 \%$, lavados en buffer fosfato salina, triturados, y homogenizados en buffer de lisis $1 \mathrm{X}$ con proteinasa $\mathrm{K}(10 \mathrm{ug} / \mathrm{ml})$.

Se realizó la extracción del ADN genómico y luego la reacción en cadena de la polimerasa (PCR) para amplificación parcial de secuencias determinadas de cuatro genes: gen htrA (lipoproteína $17 \mathrm{kDa}, 434 \mathrm{pb}$ ), gen gltA (citrato sintasa, $381 \mathrm{pb}$ ); y genes de envoltura ompA, 590 pb y ompB, 2478 pb, empleando iniciadores (primers) específicos del género Rickettsia previamente reportados $(8,9)$; y como controles positivos, el ADN de Rickettsia akari aislado de embriones de pollo y de Rickettsia felis aislado de vectores, verificados por secuenciamiento; como control negativo agua de grado molecular y como control de especificidad ADN de microorganismo no rickettsial, Leptospira $s p$. Los productos específicos de los genes amplificados, obtenidos en el PCR, fueron purificados, y secuenciados en ambas direcciones, en analizador genético 3500xl.

El análisis bioinformático consistió en el limpiado de las secuencias obtenidas utilizando los programas BioEdit V7.2.5 y Mega V.6; y ensamblado de secuencias con el programa Cap3. Las secuencias consenso fueron comparadas, por alineamiento local, con la base de datos del NCBI (National Center of Biotechnology Information). 


\section{ANÁLISIS ESTADÍSTICO}

Para las variables cuantitativas (edad, resultados de serología y resultados de aislamiento por región geográfica), se expresaron con medidas de tendencia central, media o mediana dependiendo de su distribución. Los datos cualitativos (sexo, procedencia, presencia de animales domésticos, antecedentes de contacto con artrópodos ectoparásitos, deficiencia en vivienda y saneamiento, viajes previos realizados) fueron expresados como frecuencias y porcentajes. La información fue ingresada a una base de datos elaborado en Excel y luego procesados y analizados con el programa EPI-INFO v 3.5.4. La presentación de los resultados se realizó mediante tablas de frecuencias absolutas y porcentuales.

\section{CONSIDERACIONES ÉTICAS}

El estudio conto con la aprobación del Comité de Ética del Instituto Nacional de Salud de Perú. Se guardó reserva acerca de las identidades de los sujetos encuestados, sus declaraciones, información y demás datos generados. Asimismo, los resultados de las pruebas fueron dados a conocer en códigos de trabajo.

\section{RESULTADOS}

La muestra final obtenida considerando perdidas de información durante la revisión de las fichas clínicoepidemiológicas fue de 1634 individuos en total, procedentes de 18 localidades de zonas fronterizas, dos de Loreto, cuatro de Madre de Dios, dos de Tacna y 11 de Tumbes (Figura 1).

Fueron capturados 216 artrópodos ectoparásitos (pulgas, piojos y garrapatas), 87 en Tumbes, 53 en Tacna, 20 en Loreto y 56 en Madre de Dios, obtenidos de perros y gatos de las viviendas de los encuestados.

\section{ANÁLISIS EPIDEMIOLÓGICO}

Se encontró mayor frecuencia de participantes de sexo femenino $(65,7$ vs $34,3 \%)$ en todas las regiones; la mediana de la edad de los participantes fue de 32 años con edades extremas entre 1 y 89 años (Tabla 1 ).
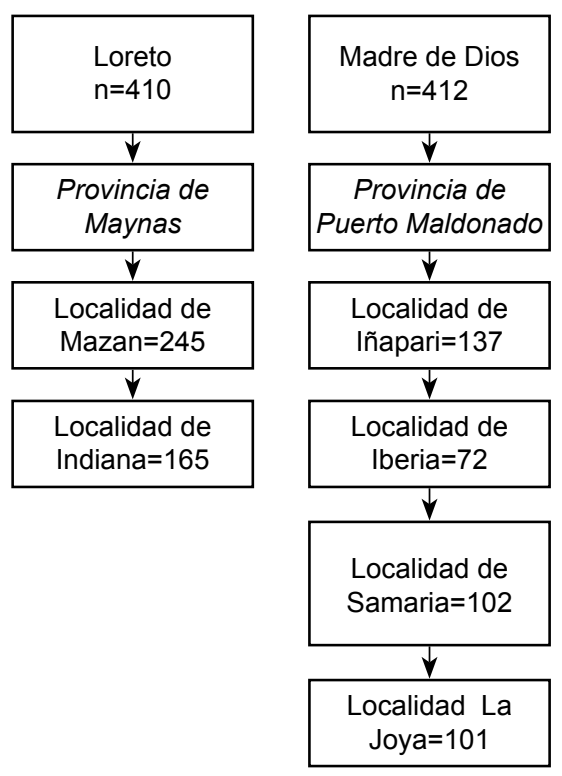
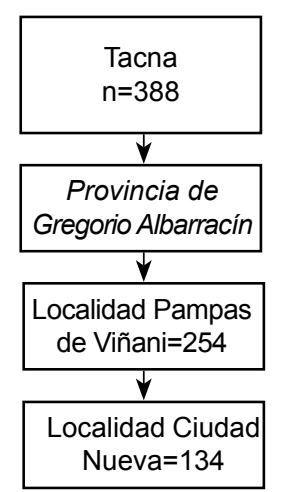$$
\text { . }
$$

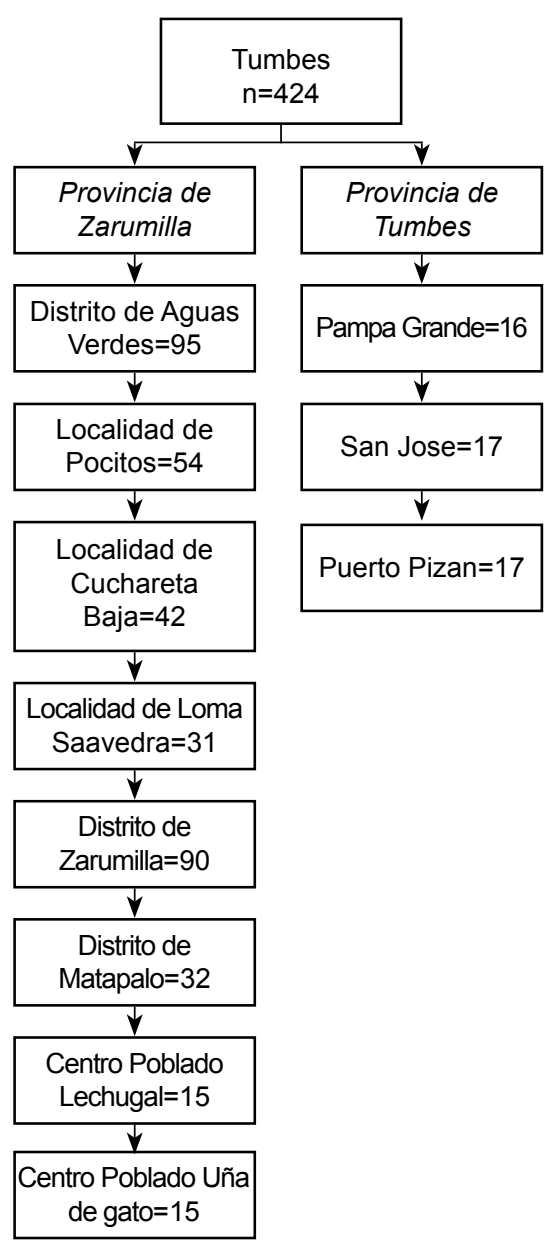

Figura 1. Distribución de la muestra entre las cuatro regiones de frontera estudiadas. 
Tabla 1. Características socio demográficas, eco epidemiológicas, serológicas y de cultivo de las rickettsiosis en las cuatro regiones estudiadas

\begin{tabular}{|c|c|c|c|c|c|}
\hline Características & Total & Loreto & Madre de Dios & Tacna & Tumbes \\
\hline Procedencia $\mathrm{n}(\%)$ & $1634(100,0)$ & $410(25,1)$ & $412(25,2)$ & $388(23,7)$ & $424(26,0)$ \\
\hline Edad, mediana (min-max) & $32(1-89)$ & $35(5-89)$ & $31(1-75)$ & $30(1-73)$ & $32(1-84)$ \\
\hline \multicolumn{6}{|l|}{ Sexo $n(\%)$} \\
\hline Femenino & $1073(65,7)$ & $238(22,2)$ & $276(25,7)$ & $260(24,2)$ & $299(27,9)$ \\
\hline Masculino & $561(34,3)$ & $172(30,7)$ & $136(24,2)$ & $128(22,8)$ & $125(22,3)$ \\
\hline \multicolumn{6}{|l|}{ Características eco epidemiológicas n/N(\%) } \\
\hline${ }^{*}$ Presencia de animales & $924 / 1634(56,5)$ & $166(18,0)$ & $262(28,4)$ & $225(24,3)$ & $271(29,3)$ \\
\hline † Contacto con artrópodos & $1330 / 1634(81,4)$ & $375(28,2)$ & $363(27,3)$ & $347(26,1)$ & $245(18,4)$ \\
\hline ‡ Deficiencia en vivienda & $454 / 1634(27,8)$ & $98(21,6)$ & $90(19,8)$ & $85(18,7)$ & $181(39,9)$ \\
\hline Viajes previos & $282 / 1634(17,3)$ & $64(22,7)$ & $67(23,7)$ & $73(25,9)$ & $78(27,7)$ \\
\hline Viajes previos a localidades más cálidas & $144 / 1634(8,8)$ & $31(21,5)$ & $29(20,2)$ & $19(13,2)$ & $65(45,1)$ \\
\hline \multicolumn{6}{|l|}{ Características serológicas y de cultivo n/N(\%) } \\
\hline Presencia de anticuerpos para rickettsias & $553 / 1634(33,8)$ & $89 / 410(21,7)$ & $136 / 412(33,0)$ & $187 / 388(48,2)$ & $141 / 424(33,3)$ \\
\hline Cultivos positivos en IFI para Rickettsias & $86 / 1634(5,3)$ & $4 / 410(1,0)$ & $14 / 412(3,4)$ & $37 / 388(9,5)$ & $31 / 424(7,3)$ \\
\hline $\begin{array}{l}\text { Positivos en cultivo, con serología } \\
\text { positiva }\end{array}$ & $40 / 86(46,5)$ & $0 / 4(0,0)$ & $8 / 14(57,1)$ & $16 / 37(43,2)$ & $16 / 31(51,6)$ \\
\hline
\end{tabular}

* Presencia intradomiciliaria o peridomiciliaria de animales como perro, gato, rata, aves de corral, ganado, entre otros

+ Antecedentes de contacto con artrópodos ectoparásitos como pulgas, piojos y garrapatas

‡ Deficiencia en vivienda y saneamiento con piso de tierra, no material noble, sin agua ni desagüe

Más de la mitad de los encuestados $(56,5 \%)$ refirió el contacto con animales domésticos tanto a nivel intradomiciliario como a nivel peridomiciliario $y$ aproximadamente cuatro de cada cinco encuestados informó contacto con artrópodos ectoparásitos como pulgas, piojos y garrapatas durante alguna vez en su vida. El 27,8\% manifestó deficiencias en sus viviendas como no utilizar material noble en su construcción, presencia de piso de tierra, y problemas de saneamiento como ausencia de agua y/o desagüe.

Un 33,8\% (553) del total de encuestados tenía anticuerpos al género Rickettsia y un 5,3\% (86) del total presentaron cultivos positivos para Rickettsia, el 15,6\% (86/553) de los positivos en serología resultaron también positivos en cultivo para aislamiento.

En Loreto se encontró 21,7\% (89) con serología positiva, pero ninguno de los cuatro cultivos que resultaron positivos en aislamiento verificado por IFI, correspondió a individuos con anticuerpos detectables. En las otras tres regiones estudiadas si se encontró seropositividad a rickettsias en aquellos que también eran positivos en cultivos, en Madre de Dios ocho tuvieron cultivo positivo de 136 positivos en serología (5,8\%), en Tacna 16 de $187(8,5 \%)$ y en Tumbes 16 de $141(11,3 \%)$.

El síntoma más frecuente reportado en el total de los encuestados fue la presencia de cefalea en casi la mitad de los encuestados $(48,4 \%)$, mientras que el síntoma menos frecuente fueron las náuseas (10,0\%) (Figura 2).
La distribución de los síntomas entre los que resultaron positivos por IFI y que tuvieron cultivo positivo (31), fueron $16(51,6 \%)$ con cefalea, $13(42 \%)$ con malestar general, nueve (29\%) con mialgia, artralgia, cinco febriles $(16 \%)$, cinco con dolor abdominal (16\%), los demás síntomas como nauseas: $3(9,67 \%)$, vómito, diarrea, entre otros, fueron poco frecuentes. Esta distribución porcentual de síntomas fue similar al total de la muestra.

\section{ANÁLISIS MOLECULAR}

31 cultivos de rickettsias propagados en sub cultivos y verificados como positivos por IFI, en el análisis molecular no evidenciaron bandas específicas. 16 de $218 \mathrm{pool}$ (grupos) de vectores fueron positivos para ADN rickettsial, obteniéndose productos de PCR específicos de $434 \mathrm{pb}$ (htrA) y de $381 \mathrm{pb}$ (gltA) (Figura 3).

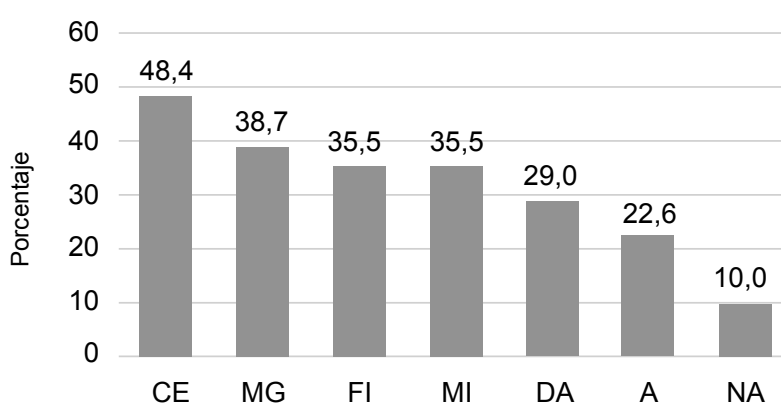

CE: Cefalea, MG: Malestar general, FI: Fiebre, MI: Mialgia, DA: Dolor abdominal, A: Asintomático, NA: Nauseas

Figura 2. Frecuencia de síntomas encontrados en pobladores de localidades de frontera peruana 2010-2011. 

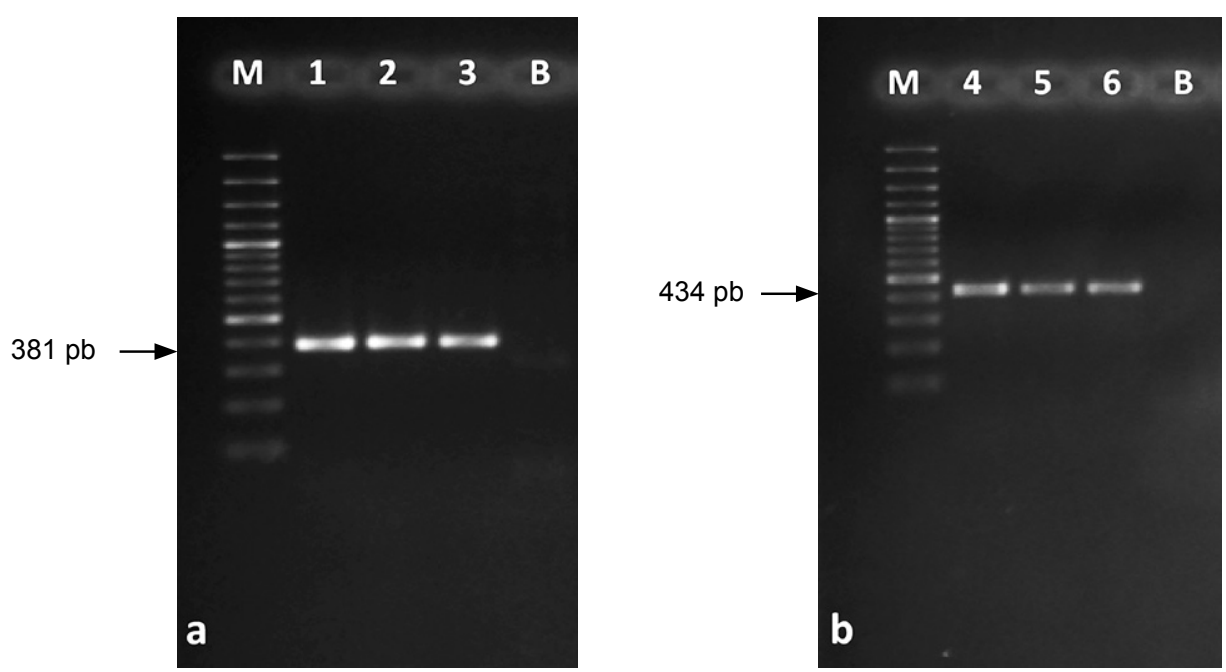

Figura 3. PCR del gen gltA (a) y htrA (b) a partir de ADN total provenientes de pulgas Ctenocephalides felis colectados en perros y gatos de zonas fronterizas del Perú. M: Marcador de 100 pares de bases. Carril 1-6: ADN extraído de vectores provenientes de regiones fronterizas del Perú

Mediante el secuenciamiento de los genes $h$ trA y gltA; y el análisis del grado de homología (basado en una evaluación de identidad $\geq$ al $99 \%$, y una cobertura $\geq$ al $98 \%$ ); se identificó Rickettsia felis en Ctenocephalides felis de perros y gatos de Tacna; y una especie nueva para la región y para Perú: Candidatus Rickettsia asemboensis en pulgas Ctenocephalides felis de gatos y perros de Loreto y Madre de Dios. El análisis de los genes parciales ompA (590 pb) y ompB (2478pb) amplificados y secuenciados, confirmaron los resultados obtenidos (Tabla 2).

Tabla 2. Especies de rickettsias identificadas en $16 \mathrm{pool}$ de ectoparásitos capturados en animales domésticos de zonas fronterizas del Perú, cuyos ADN amplificaron exitosamente en reacción en cadena de polimerasa (PCR).

\begin{tabular}{|c|c|c|c|c|c|c|}
\hline \multirow{2}{*}{\multicolumn{3}{|c|}{$\begin{array}{l}\text { Procedencia de las muestras de ADN } \\
\text { rickettsial de ectoparásitos }\end{array}$}} & \multicolumn{4}{|c|}{$\begin{array}{c}\text { Especie identificada } \\
\text { Grado de homología (Identidad } \geq 99 \% \text {; Cobertura } \geq 98 \% \text { ) }\end{array}$} \\
\hline & & & \multicolumn{4}{|c|}{ Genes secuenciados } \\
\hline Pool & Región & Huésped & htrA & gltA & ompA & ompB \\
\hline 1 & Tacna & perro & R. felis & R. felis & R. felis & R. felis \\
\hline 2 & Loreto & gato & Rickettsia sp. & Ca. R. asemboensis & * & Ca. R. asemboensis \\
\hline 3 & Loreto & perro & Rickettsia sp. & Ca. R. asemboensis & * & Ca. R. asemboensis \\
\hline 4 & Madre de Dios & perro & Rickettsia sp. & Ca. R. asemboensis & * & Ca. R. asemboensis \\
\hline 5 & Madre de Dios & perro & Rickettsia sp. & Ca. R. asemboensis & * & Ca. R. asemboensis \\
\hline 6 & Madre de Dios & gato & Rickettsia sp. & Ca. R. asemboensis & * & Ca. R. asemboensis \\
\hline 7 & Madre de Dios & No registrado & Rickettsia sp. & Ca. R. asemboensis & * & * \\
\hline 8 & Tacna & No registrado & R. felis & R. felis & R. felis & * \\
\hline 9 & Tacna & gato & R. felis & R. felis & R. felis & * \\
\hline 10 & Tacna & perro & R. felis & R. felis & R. felis & * \\
\hline 11 & Tacna & perro & R. felis & R. felis & R. felis & * \\
\hline 12 & Loreto & perro & Rickettsia sp. & Ca. R. asemboensis & * & Ca. R. asemboensis \\
\hline 13 & Loreto & gato & Rickettsia sp. & Ca. R. asemboensis & * & * \\
\hline 14 & Loreto & perro & Rickettsia sp. & Ca. R. asemboensis & * & Ca. R. asemboensis \\
\hline 15 & Madre de Dios & perro & Rickettsia sp. & Ca. R. asemboensis & * & Ca. R. asemboensis \\
\hline 16 & Madre de Dios & perro & Rickettsia sp. & Ca. R. asemboensis & * & Ca. R. asemboensis \\
\hline
\end{tabular}

* Regiones no secuenciadas.

Ca. R. asemboensis: Candidatus Rickettsia asemboensis

R. felis: Rickettsia felis 


\section{DISCUSIÓN}

Para demostrar la circulación de rickettsias en las zonas estudiadas, nuestros hallazgos se basan en dos ejes principales, la evidencia serológica mediante prueba IFI, la más utilizada para estudios de seroprevalencia y como método diagnóstico frente a infecciones por rickettsias por ser de fácil acceso y manejo en diferentes regiones ${ }^{(20)}$. El segundo criterio, de mayor significado para la definición específica en la identificación de rickettsias fueron las pruebas moleculares, con las que se pudo demostrar la presencia de al menos dos especies de rickettsias circulantes en tres de las regiones encuestadas.

Una de las especies identificadas es Rickettsia felis, cuya presencia en el Perú ya ha sido reportada ${ }^{(8)}$. Es un patógeno emergente descrito por primera vez en $1990{ }^{(21)}$, con reportes en diversas partes del mundo, tanto en humanos como en otros mamíferos y en pulgas. El 2004 se presentó un brote de enfermedad febril en humanos atribuida en parte a infección rickettsial por fiebre manchada en tres localidades de la región noroeste del Perú ${ }^{(8)}$, se identificó a Rickettsia felis por secuenciamiento parcial del gen del antígeno común de 17-kDa (htrA) y comparación en homología de secuencia nucleotidica con los genes: glt $A$, ompA, and $o m p B$ en muestras obtenidas a partir de pulgas. Sin embargo, la mayor parte de casos permanece pobremente caracterizada, probablemente debido a la carencia de síntomas y signos específicos y a la baja disponibilidad de pruebas confirmatorias.

La presentación clínica de la enfermedad por Rickettsia felis es similar a la del tifus murino (Rickettsia typhi) y a otras febriles, por ello la infección con frecuencia es subestimada. Es importante establecer el grado de participación de ésta etiología en casos de infección febril inespecífica, por lo que su identificación durante el presente estudio resulta significativa, considerando que grupos de expertos estiman que debería ser considerada un reto emergente a la salud humana ${ }^{(21)}$.

La otra especie identificada en nuestro estudio, a partir de ectoparásitos fue Candidatus Rickettsia asemboensis, reportada en pulgas el año 2009 en Asembo, Kenya, mediante tipificación de la secuencia multilocus empleando genes de 17-kD, rrs, gltA, ompA, ompB, y sca4, demostrando estrecha relación con Rickettsia felis ${ }^{(22)}$, siendo no obstante lo suficientemente distinta para ser considerada como una especie aparte dentro del grupo de las fiebres manchadas. Esta especie ha sido notificada recientemente en Ecuador ${ }^{(23)}$, donde no habían reportes acerca de microorganismos asociados a pulgas, y en Colombia, en donde se le ha encontrado asociada a garrapatas de animales domésticos (24); para el Perú se tienen dos reportes últimos, uno estrechamente relacionado al presente estudio ${ }^{(25)}$ y el otro que incluye una de las regiones aquí estudiadas, Loreto, en esta investigación encontraron una alta prevalencia de la presencia de esta especie en población de pulgas de animales domésticos, sugiriendo la posibilidad de transmisión hacia humanos, lo cual hasta el momento no ha sido comprobado ${ }^{(26)}$.

El hecho que en las regiones estudiadas la presencia de animales domésticos y/o peridomiciliarios en promedio sea superior al $50 \%$ y que los porcentajes para contacto previo con artrópodos ectoparásitos, probables vectores, haya sido tan elevado como del $80 \%$, confirma el entorno epidemiológico que caracteriza la presentación de las infecciones rickettsiales en todo el mundo ${ }^{(1,3)}$. En el Perú, como en países vecinos en donde las mascotas y animales domésticos (gatos, perros, conejos, cuyes, etc.) entran en contacto con roedores peridomiciliarios y sinantrópicos, resulta necesario estudiar los probables candidatos a reservorios y vectores involucrados, a fin de establecer medidas de prevención y control. Es destacable, que estudios realizados en Argentina y Uruguay $(27,28)$ hallan establecido la cadena epidemiológica de la fiebre manchada de las Montañas Rocosas en Sudamérica, dando a conocer a varias especies de garrapatas como vectores y a la especie Rickettsia parkeri como el agente etiológico responsable de las rickettsiosis del grupo de fiebres manchadas en zonas endémicas de esta parte del continente.

La condición endémica de la presencia de rickettsias en las localidades estudiadas estaría evidenciada por la presencia de numerosos sujetos asintomáticos, lo cual sugeriría atenuación de síntomas, perdiendo en muchos casos su expresión patogénica, debido a reducción de genomas en las especies circulantes ${ }^{(29)}$, involucrando a su vez interesantes interacciones entre el huésped, el vector y el patógeno ${ }^{(30)}$. Esto podría aplicar para las dos especies identificadas en el presente estudio, lo cual amerita monitoreo epidemiológico y vigilancia continua en probables vectores y reservorios amplificadores para estar preparados en el tiempo ante la posibilidad de surgimiento de enfermedades emergentes y reemergentes de este tipo ${ }^{(4)}$.

La principal limitación de nuestro estudio fue la poca oportunidad para obtener muestras de sujetos febriles, lo cual reprodujo bajas cargas microbianas en los cultivos, condicionando que no pudieran ser confirmados por PCR. Para futuros estudios, se prevé el empleo de iniciadores de amplificación de mayor alcance, tal como los anidados, a fin de optimizar la detección molecular a partir de cultivos celulares de muestras humanas durante su propagación. Además, las pruebas moleculares realizadas en artrópodos se llevaron a cabo en pool y no en ejemplares individuales, a fin de obtener mayor rendimiento. 
En conclusión, se ha demostrado la circulación de rickettsias durante el periodo de estudio en las localidades encuestadas y se ha logrado identificar dos especies de rickettsias del grupo de fiebres manchadas, a partir de artrópodos ectoparásitos procedentes de localidades fronterizas en tres de las regiones estudiadas (Madre de Dios, Loreto y Tacna), estando para todos los casos, involucrada la pulga Ctenocephalides felis, tanto de perros como de gatos. Los análisis moleculares basados en los genes parciales $h t r A$, glt $A$, ompA y ompB, identificaron presencia de Rickettsia felis en Tacna. Para Loreto y Madre de Dios fue identificada otra especie muy similar y con quien comparte características comunes, la denominada Candidatus Rickettsia asemboensis recientemente reportada para la región.

La estandarización, implementación, desarrollo y aplicación de técnicas biológicas y moleculares especializadas, con motivo de éste estudio fortalece la capacidad institucional y nacional para lograr un sistema de vigilancia eficaz de las rickettsiosis en territorio peruano, tal como está siendo aplicado en otras latitudes. Resulta pertinente y necesario continuar con la investigación en esta área, en un contexto más amplio, incluyendo estudios en reservorios y aplicando procedimientos de laboratorio cada vez más sensibles y específicos, lo cual requiere información actualizada acerca de las características biológicas, moleculares y epidemiológicas de las especies involucradas.

Agradecimientos: Al Dr. César Cabezas, gestor e impulsador del INS para la Maestría en Salud Pública en Convenio con la Fundación Oswaldo Cruz de Brasil. A las doctoras Lely Solari y Elizabeth Sánchez por su valioso apoyo al financiamiento y realización del presente trabajo. A todas las personas involucradas en el protocolo previo, en especial a las autoridades de las Direcciones Regionales de Salud (DIRESA) de Loreto, Madre de Dios, Tumbes y Tacna. A los profesionales responsables de los Laboratorios de Metaxénicas Bacterianas, Bióloga MSc. Giovanna Mendoza y de Biología Molecular, Dr. Heinner Guio, por las facilidades brindadas. A las doctoras Elba Lemos y Tatiana Rozental Burdman del Instituto FioCruz por su apoyo al brindarnos protocolos de secuenciamiento y purificación. Al Microbiólogo Yerson Durán Ramírez por su valiosa colaboración en la primera etapa del desarrollo de la investigación. A las profesoras Alicia Ugá y Sheila Lemos de FioCruz, y a Jenny Sánchez del INS, todas eficientes coordinadoras de la Maestría y colaboradoras.

Contribución de autores: RPS conceptuó y redactó el manuscrito, EAR colectó los datos e hizo revisión crítica, JJL procesó, analizó e interpretó los datos en aspectos moleculares, OCR y FCS hicieron revisión crítica, LMU y PMV aportaron en procedimientos metodológicos y diseño del manuscrito. Todos aprobaron la versión final.

Fuentes de financiamiento: el estudio fue financiado por el Instituto Nacional de Salud de Perú, a través del Centro Nacional de Salud Pública.

Declaración de conflictos de interés: los autores declaran no tener conflictos de interés.

\section{REFERENCIAS BIBLIOGRÁFICAS}

1. González M, Mattar S. Ratas, ácaros, guerras, pobreza, negligencia y rickettsiosis. Rev MVZ Córdoba. 2011;16(2): 2433-4.

2. Valbuena G. Rickettsiosis: pathogenesis, inmunidad y desarrollo de vacunas. Acta méd costarric. 2013;55(3):48-59.

3. Buitrago DA, Pachón HE. Epidemiología de las Rickettsiosis. Una Revisión Narrativa. Aportes para la Vigilancia Epidemiológica. Medidas de presentación y factores asociados. [tesis] Medellín: Universidad de Antioquia, Facultad Nacional de Salud Pública, 2008.

4. Walker, DH. Rickettsiae and rickettsial infections: the current state of knowledge. Clin Infect Dis. 2007;45 Suppl 1:S39-44. doi: 10.1086/518145.

5. Galvão M, Freitas A. Enfermedades rickettsiales:¿Un problema de salud pública en América Latina? Acta méd costarric. 2013;55(3):7-10.

6. Fonseca L, Marcello G, Martins AV. Febre Maculosa: Revisão de literatura-artigo de revisão. Saúde \& Ambiente. 2009;2(1):1-20.

7. Forshey BM, Stewart A, Morrison AC, Gálvez H, Rocha C, Astete H, et al. Epidemiology of spotted fever group and typhus group rickettsial infection in the Amazon basin of Peru. Am J Trop Med Hyg. 2010; 82(4):683-90. doi: 10.4269/ajtmh.2010.09-0355.

8. Blair PJ, Jiang J, Schoeler GB, Morón $\mathrm{C}$, Anaya E, Céspedes $\mathrm{M}$, et al. Characterization of spotted fever group rickettsiae in flea and tick specimens from northern Peru. J Clin Microbiol.2004; 42(11):4961-7. doi: 10.1128/JCM.42.11.4961-4967.2004

9. Jiang J, Blair PJ, Felices V, Moron C, Cespedes M, Anaya E, et al. Phylogenetic Analysis of a Novel Molecular Isolate of Spotted Fever Group Rickettsiae from Northern Peru Candidatus Rickettsia andeanae. Ann N Y Acad Sci. 2005; 1063:337-42.

10. Flores-Mendoza C, Florin D, Felices V, Pozo EJ, Graf PC, Burrus RG, et al. Detection of Rickettsia parkeri from within Piura, Peru, and the first reported presence of Candidatus Rickettsia andeanae in the tick Rhipicephalus sanguineus. Vector Borne Zoonotic Dis. 2013;13(7):505-8. doi: 10.1089/ vbz.2012.1028.

11. Cáceres AG, Padilla Rojas CP, Arias Stella J, Huatuco Crisanto G, Gonzales Pérez A. La detección de Bartonella spp. y Rickettsia spp. en pulgas, garrapatas y piojos recolectados en las zonas rurales de Perú. Rev peru biol. 2013;20(2):165-9.

12. Hidalgo M, Faccini-Martínez AA, Valbuena G. Rickettsiosis transmitidas por garrapatas en las Américas: avances clínicos y epidemiológicos, y retos en el diagnóstico. Biomédica 2013; 33 Suppl 1:161-78

13. Sistema de Información Geográfica [internet], Lima: Instituto Nacional de Estadística e Informática. Acceso 15 de febrero de 2016. Disponible en: http://sige.inei.gob.pe/test/atlas/.

14. Ministerio de Relaciones Exteriores. Dirección de Desarrollo e Integración 
Fronteriza. Lima: Ministerio de Relaciones Exteriores, 2012.

15. La Scola B, Raoult D. Laboratory diagnosis of rickettsioses:current approaches to diagnosis for old and new rickettsial diseases. J Clin Microbiol 1997; 35(11):2715-27.

16. Oteo JA, Nava $S$, de Sousa R, Mattar $S$, Venzal JM, Abarca K, Labruna MB y Zavala-Castro J. Guias Latinoamericanas de la RIICER para el diagnóstico de las rickettsiosis. Rev Chilena Infectol 2014; 31(1):54-65. doi: 10.4067/S071610182014000100009 .

17. Weinert LA, Werren JH, Aebi A, Stone GN, Jiggins FM. Evolution and diversity of Rickettsia bacteria. BMC Biol. 2009;7:6. doi: 10.1186/1741-7007-7-6.

18. Linardi $\mathrm{PM}, \quad$ Guimarães LR. Sifonápteros do Brasil. São Paulo: Museu de Zoologia USP/Fapesp, 2000.

19. Barros-Battesti, D.M.; Arzua, M.; Bechara, G.H. Carrapatos de importância médico-veterinária da região neotropical: um guia ilustrado para identificação de espécies. São Paulo: Integrated Consortium on Ticks \& Tick-borne Diseases (ICTTD-3),2006.

20. Paddock CD. Perspectivas sobre el diagnóstico de laboratorio de enfermedades rickettsiales en el siglo 21. Acta méd costarric 2013; 55 (3): 13-24.

21. Pérez-Osorio CE, Zavala-Velázquez JE, Arias León JJ, y Zavala-Castro JE. Synopsis Rickettsia felis as Emergent
Global Threat for Humans. Emerg Infect Dis. 2008;14(7):1019-23. doi: 10.3201/eid1407.071656.

22. Luce-Fedrow A, Maina AN, Otiang E, Ade F, Omulo S, Ogola E, et al. Isolation of Candidatus Rickettsia asemboensis from Ctenocephalides Fleas. Vector Borne Zoonotic Dis 2015; 15(4):268-77. doi: 10.1089/ vbz.2014.1744.

23. Oteo JA, Portillo A, Portero F, ZavalaCastro J, Venzal JM, Labruna MB. 'Candidatus Rickettsia asemboensis' and Wolbachia spp. in Ctenocephalides felis and Pulex irritans fleas removed from dogs in Ecuador. Parasit Vectors. 2014;7: 455. doi: 10.1186/ s13071-014-0455-0.

24. Faccini-Martínez A, RamírezHernández A, Forero-Becerra,E, Cortes-Vecino JA, Escandón P, Rodas JD et al. Molecular Evidence of Different Rickettsia Species in Villeta, Colombia. Vector Borne Zoonotic Dis. 2016;16(2):85-7. doi: 10.1089/ vbz.2015.1841.

25. Palacios-Salvatierra R, Anaya-Ramírez E, Juscamayta-López J, Cáceres-Rey O, Mendoza-Uribe L, Mosquera P, et al. Perfil epidemiológico y molecular de las rickettsiosis en zonas de frontera peruana - añoS 2010-2011 [Internet]. Rev Biomed. 2015;26 Supl 1:99-100 [citado el 20 de diciembre de 2015]. Disponible en: http://www.revbiomed.uady.mx/ pdf/rb1526S146.pdf

26. Kocher C, Morrison AC, Leguia M, Loyola S, Castillo RM, Galvez HA, et al. (2016) Rickettsial Disease in the Peruvian Amazon Basin. PLoS Negl
Trop Dis. 2016;10(7):e0004843. doi: 10.1371/journal.pntd.0004843. eCollection 2016.

27. Romer Y, Seijo AC, Crudo F, Nicholson WL, Varela-Stokes A, Lash RR et al. Rickettsia parkeri rickettsiosis, Argentina. Emerg Infect Dis. 2011;17(7):1169-73. doi: 10.3201/eid1707.101857.

28. Venzal JM, Estrada-Peña A, Portillo A, Mangold AJ, Castro O, De Souza CG, et al. Rickettsia parkeri: A Rickettsial pathogen transmitted by ticks in endemic areas for Spotted Fever Rickettsiosis in southern Uruguay. Rev Inst Med Trop Sao Paulo. 2012;54(3):131-4.

29. Blanc G, Ogata H, Robert C, Audic S, Suhre K, Vestris G, et al. Reductive Genome Evolution from the Mother of Rickettsia. Plos Genet. 2007;3(1):e14. doi: 10.1371/journal.pgen.0030014.

30. Randolph SE. Tick-borne disease systems emerge from the shadows: the beauty lies in molecular detail, the message in epidemiology. Parasitology. 2009; 136(12):1403-13. doi: 10.1017/ S0031182009005782.

Correspondencia: Rosa Palacios Salvatierra Dirección: Laboratorio de Metaxénicas Bacterianas - Instituto Nacional de Salud Cápac Yupanqui 1400 - Jesús María, Lima 11, Perú.

Teléfono: (511) 7481111 - anexo 2103

Correo electrónico:rpalaciossalvatierra@gmail.com

\section{Nuestros artículos se encuentran indizados en:}

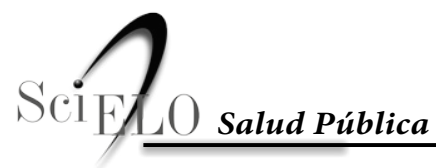

www.scielo.org 